\title{
The Design and Inspection of the Thermocouple in the Breakout Prediction System
}

\author{
Caifeng Chen \\ College of Mechanical Engineering, University of Shanghai for Science and Technology \\ 516 Jun Gong Road, Shanghai 200093, China \\ Tel: 86-21-5527-0638Ｅ-mail: chencaifeng@usst.edu.cn \\ Xinhua Wang \\ College of Mechanical Engineering, University of Shanghai for Science and Technology \\ 516 Jun Gong Road, Shanghai 200093, China \\ Tel: 86-21-5527-3617 E-mail:wangxinhua@hotmail.com
}

\begin{abstract}
Using practical solutions and exuberant experience in installation and inspection as the background and basic theories, this essay has analyzed and demonstrated the optimal design and installation and inspection techniques of the thermocouple on the crystallizer in the breakout prediction system. The content of this essay is informative and specific, and it has a higher practicality in related field of casting breakout prediction techniques.
\end{abstract}

Keywords: Thermocouple, Continue casting, Breakout prediction system, Crystallizer

\section{Introduction}

In the breakout prediction system of casting steel, the method of measuring thermocouple Temperature is applicated, nearly by promoting the accuracy. the major technology is to install thermocouple in the wall of crystallization so as to collect, test, display and handle easy Temperature changing data of the local areas of the crystallization, and make the corresponding alarm of molten steel leakage by the seriousness (yellow or red card) to the operating personnel, finally finish the process of automatically control and guide worker to product and operate, which can decrease the (number) chance of molten steel leakage and avoid an accident.

\section{The optimized design of planned spacing in the crystallization}

K-thermocouple in the wall of Crystallization, its planned spacing, that is, the measuring spacing of thermocouple Temperature matches the spread speed at a mouthful of billet shell in molten steel leakage or not, will impact directly the accuracy and the response to speed of steel leakage forecast system. Therefore, first of all, the planned spacing should be calculated and optimized.

The spreading speed of the breakup of Casting billet shell is related to the casting speed of continue caster. When the casting speed of continue caster is $\mathrm{v}_{\mathrm{c}}$, for the horizontal speed of the fracture billet shell is $\mathrm{v}_{\mathrm{x}}$, the vertical speed is $\mathrm{v}_{\mathrm{y}}$, the rate to the casting speed $\alpha$ (experience value $0.55 \sim 0.90$ ) has:

$$
\alpha=\frac{V_{\mathrm{y}}}{V_{\mathrm{c}}}
$$

A planned horizontal spacing of the crystallization of copper is $w_{x}$, the vertical space is $w_{y}$, $\beta$ is the angle to billet shell broken line with the horizontal line, as shown in figure 1.

$$
\tan \beta=\frac{V_{\mathrm{y}}}{V_{\mathrm{x}}}
$$

For the time for broken line of billet shell extending a temperature spacing in horizontal and vertical is $t_{x}$ and $t_{y}$, and the horizontal vertical spread time:

$$
t_{x}=\frac{W_{x}}{V_{x}}=\frac{W_{x} \tan \beta}{V_{y}}=\frac{W_{x}}{\alpha V_{c} \cot \beta_{c}}
$$

The Vertical spread time: 


$$
t_{y}=\frac{W_{y}}{V_{y}}=\frac{W_{y}}{\alpha V_{c}}
$$

There are two ways to get value $\beta$ :

(1) According to measured value remaining in billet shell line of crystallization, when the range $0.7 \sim 1.6 \mathrm{~m} / \mathrm{min}$, measured value is $30^{\circ} \sim 45^{0}$;

(2) With experimental value $t_{x}$ and $t_{y}$, the $v_{x}$ and $v_{y}$ in the following formula:

$$
\beta=\arctan \left(\frac{V_{y}}{V_{x}}\right)=\arctan \left(\frac{W_{y} t_{x}}{W_{x} t_{y}}\right)
$$

$\beta$ is about $20^{\circ} \sim 45^{\circ}$, for example, when the planned horizontal spacing of the crystallization copper $\mathrm{w}_{\mathrm{x}}$ is $220 \mathrm{~mm}$, the vertical space $\mathrm{w}_{\mathrm{y}}$ is $220 \mathrm{~mm}$, the horizontal and vertical spread time difference of the molten steel leakage:

Horizontal spread time for a space: $t_{x}=\frac{W_{x} \tan \beta}{\alpha V_{\mathrm{c}}}=\frac{220 \tan \beta}{\alpha V_{C}}$

Vertical spread time for a space: $\quad t_{y}=\frac{W_{y}}{\alpha V_{c}}=\frac{220}{\alpha V_{c}}$

As $25^{\circ} \leq \beta \leq 45^{\circ}, 220 \times \tan \beta \leq 220, \quad t_{x} \leq t_{y}$.

As $\tan \beta=\mathrm{t}_{\mathrm{x}} / \mathrm{t}_{\mathrm{y}}$, the relationship of horizontal and vertical spreading speed: $\mathrm{V}_{\mathrm{x}} \approx(2.14 \sim 1) \mathrm{V}_{\mathrm{y}}$

Thus, the speed of delivery of horizontal temperature is more than the vertical speed, when the plan time interval is the same, as forecasting the adhesion, the temperature of the delivery speed is quicker than the vertical speed.

To enhance Accuracy of the steel leakage forecasting system, The temperature should be detected on both directions to reduce failures in reporting or missing; being optimized, the spread time in both directions must be equal, that is, $\mathrm{t}_{\mathrm{x}}=\mathrm{t}_{\mathrm{y}}$, the relationship as shown in the flowing: $\mathrm{W}_{\mathrm{y}}=\mathrm{W}_{\mathrm{x}} \tan \beta$

This is theoretical basis in calculating the planned spacing while the thermocouple is installed in crystallization.

\section{The selection of thermocouple}

Choosing a right thermocouple will not only get the exact temperature value and conformity products, but also may reduce material consumption to save money and to ensure the quality of products. in order to guarantee the thermocouple working Reliably and safe in bad circumstances (working environment temperature range $-20^{\circ} \mathrm{C} \sim 200^{\circ} \mathrm{C}$, with an amount of water vapor and a small amount of oil fields, and space limitation, together with the vibration), our system uses non-standard K-thermocouple.

As in figure 2, it consists of eight parts with firm structure, magnesium insulation resistance is good and has not short circuit; the stainless steel casing can isolate fully harmful media, and compensates welding connection between the wire and free port of the thermocouple and processes with sweating; the front are screwed with the thread of more than two remaining teeth, and outer seal nut matches with PTEE seal and bolts of double head to ensure gathering the temperature data of the lower in crystallizer.

Technical parameters instance from all parts of the thermocouple is showed as table1 4.

Pay attention that length of bolts hole and aperture from different crystallization may vary, or is redesigned or inflexible. It should consider installing process of the thermocouple and calculate the length of thermocouple and spring accurately etc. the length allowance of thermocouple is less than $1 \mathrm{~mm}$, and that of the spring is less than 3 $\mathrm{mm}$.

\section{Install processes of thermocouple}

To ensure that the Indicators of thermocouple meet the requirement, the crystallization must be reformed to ensure the quality of install process.

(1) Design features of crystallization

the Crystallization sheet is panel veneer by roughly machining with $1.5 \mathrm{~mm}$ machining allowance, Shown in figure 3 , it is a $46.5 \times 190 \times 900$ section of copper sheet, on the central position there is a hole with diameter 4.5 $\mathrm{mm}$ and depth $7 \mathrm{~mm}$ and it is a gathering point of thermocouple temperature.

(2) Main process points of Crystallization installation

Support the copper to the board by the expansion stud with stated tighten moment, through sealing test of 
$1 \mathrm{Mpa}$ water pressure and after conformity process it to stated size; all impurities caused by processing must be cleaned up (without water and oil )to ensure thermocouple accuracy. In addition, a hole is processed on the center of bolt to ensure thermocouple goes through it, and the thread linking with thermocouple is also processed in the back of it, and then hardened and tempered.

Install the thermocouple sensors into the bottom of $4.5 \mathrm{~mm}$ hole of the copper and tight it; and bolts are tighten and sealed. This seal can prevent the water steam goes into to influence measure temperatures of thermocouple.

After installing thermocouple in Crystallization, all the signal cables of thermocouple are connected with corresponding relay cases hanging up to the crystallized with compressed air of $3 \mathrm{~kg}$ pressure protecting; in addition, the planned time, to guarantee installing thermocouple that there is a position of thermocouple in the water tank of the crystallization so as to weld stainless steel pipe with thermocouple going through.

Thermocouple compensate wires connect with the remote compensate wires with switching quickly device in the framework of the Crystallization. Before compensate wires connecting transfer box, they should installed the casing against high temperature for their being exposed outside of the Crystallization to prevent steel leakage and contacting steel water.

A vent should be set in the transfer box to blow wind for protecting cases and keep dry inside it. A shield tube (diameter $\phi 40 \mathrm{~mm}$ ) should be set in the closure of compensate wires and then tight them with a setting or throat to avoid compensate wires nudity outside when it slips. We must pay attention to the model and polarity using Thermocouple compensate wires, the Temperature in the connection of Compensate wires and thermocouple could not more than $100^{\circ} \mathrm{C}$.

It will create the major errors of thermocouple when thermocouple is set error, for example, installing position and inserting depth of thermocouple could not reflect the real temperature of copper sheet. Therefore, inserting depth of thermocouple should be at least 8 to 10 times as the diameter of the protection case; for there is no insulation material between protection tube of thermocouple and wall so that heat $\mathrm{t}$ gas overflows and cooling water invades it should be sealed with PTEE between protection tube of thermocouple and Crystallization hole.

At the same time, we should try to avoid strong magnetic and electric field and not to put thermocouple and power cable in one conduit to avoid the error caused by the disturbance. replacing thermocouple when it is damaged, we should install it in the hole and tighten it with a wrench bolt; we push PTEE sealing ring the gap between tapered bolt and compensation wire and tighten sealing nut properly without tighting seriously so as to damage PTEE sealing ring.

\section{Detect way to thermocouple}

In order to guarantee installing quality and eliminate the error signal during installation process, we must test all the thermocouple.

Detection methods off-line: mark each position of $\mathrm{n}$ thermocouple of copper sheet in turn, and record the temperature that thermocouple shows at ambient temperature, for the number of thermocouple and the temperature are recorded as $\mathrm{T}_{11}, \mathrm{~T}_{12}, \ldots, \mathrm{T}_{1 \mathrm{n}}$. then adjust gas welding to the neutral flame to bake each mark point about 15 seconds; and record the temperature that thermocouple shows when baked, for they are $T_{21}, T_{22}, \ldots, T_{2 n}$.

In addition, in order to reduce detecting influence among each mark point, the operation order of roasted point can test in odd or even sequence so that we can take test point with the greatest distance and not to miss detecting point with minimum errors.

We can determine temperature difference whether to meet the requirements of formula .in accordance with the following three conditions to analysis data.

$$
\begin{gathered}
\Delta \mathrm{T}_{\mathrm{x}}=\max \left(T_{1 i}-T_{1 j}\right) \leq 1.8^{\circ} C \\
\Delta \mathrm{T}_{\mathrm{y}}=\max \left(T_{2 i}-T_{2 j}\right) \leq 4.5^{\circ} C \\
\Delta \mathrm{T}_{\mathrm{z}}=\min \left(T_{2 i}-T_{1 j}\right) \geq 8.2^{\circ} C \\
(\mathrm{i}=1,2, \ldots, \mathrm{n} \mathrm{j}=1,2, \ldots, \mathrm{n})
\end{gathered}
$$

Reason for temperature difference, the first is manual operation; the second is device differences, and the third is system influence. Therefore, this is not only indicators of quality of design and installation, but also that of system. For $\mathrm{T}_{\mathrm{ij}}$ point being discontent to condition it is not difficult to identify accurately the corresponding thermocouple and line fault, before using the device, we can eliminate it to security steel leakage forecast system to display.

Inspection on-line: The testing error of temperature will be larger because of device and material being polluted, 
deformation, oxidation insulation resistance beyond production and it will be more serious in high temperature. This not only causes wastage of hot electric potential, but also introduces interference; therefore, the error of resulting temperature is sometimes up to 100 degrees. If we use computer forecast system of steel leakage by systems, it can scan and analysis point $T_{i j}$ timing, and can judge whether or not the value of point $T_{i j}$ changes and range ability is in the normal range. If there are exceptions, the operator will shield the corresponding monitoring point, or automatic shield corresponding monitoring point. At the same time, the system prompts running maintenance personnel spot checks in time in order to achieve inspection capabilities on-line automatic.

\section{Conclusion}

In forecasting system of casting steel leakage, making design, installation and testing of thermocouple well would greatly enhance reliability of system, reduce the maintenance work greatly, and make forecasting of system steel leakage productive.

\section{Acknowledgment}

This work is Supported by Shanghai Leading Academic Discipline Project,Project Number:J50503

\section{References}

Minghong. Lishimin. (2002). Influence for compensation wires to thermocouple test results. journal of southwest petroleum institute. 5 . V24 6 78.

Shi wenkang Yu xiaofen. (2010). Detection technology. The third edition. Beijing: Machinery industry press. (Chapter 3).

Wang yazhen. (2005). technology and equipment for cast steel. Beijing: Metallurgy industry press. (Chapter 1).

Table 1. The components

\begin{tabular}{|l|l|}
\hline Indicators name & indicators data \\
\hline thermocouple perating temperature & $\geq 200^{\circ} \mathrm{C}$ \\
\hline thermocouple graduation & $\mathrm{K}$ type \\
\hline Thermocouple class & $0.4, \pm 0.4 \%$ full quantum \\
\hline encapsulate form of The components & isolated and sheathed \\
\hline insulation material & magnesium oxide \\
\hline $\begin{array}{l}\text { insulation resistance between the positive and } \\
\text { negative charges }\end{array}$ & $>100 \mathrm{M} \Omega$ \\
\hline external diameter of protective tube & $2.0 \mathrm{~mm}$ \\
\hline thermal response time $\tau 0.5$ & $\leq 0.5 \mathrm{~second}$ \\
\hline
\end{tabular}

Table 2. Spring

\begin{tabular}{|l|l|}
\hline Indicators name & indicators data \\
\hline inside diameter & $4.0 \mathrm{~mm}$ \\
\hline external diameter & $4.0 \mathrm{~mm}$ \\
\hline material & rustless steel Spring \\
\hline
\end{tabular}

Table 3. Rivets (the case of $2.0 \mathrm{~mm}$ thermocouple)

\begin{tabular}{|l|l|}
\hline Indicators name & indicators data \\
\hline external diameter & $4.0 \mathrm{~mm}$ \\
\hline material & Copper \\
\hline
\end{tabular}


Table 4. Technical specifications of Connection (with socket device) and compensate wire

\begin{tabular}{|l|l|l|l|}
\hline Indicators name & indicators data & Indicators name & indicators data \\
\hline $\begin{array}{l}\text { Thermocouple } \\
\text { fastener screw thread }\end{array}$ & $\begin{array}{l}\text { Corresponding } \\
\text { Rp1/4,threads }\end{array}$ & $\begin{array}{l}\text { the temperature of } \\
\text { compensating lead }\end{array}$ & $\geq 100^{\circ} \mathrm{C}$ \\
\hline $\begin{array}{l}\text { Thermocouple } \\
\text { fastener inside } \\
\text { diameter }\end{array}$ & $4.0 \mathrm{~mm}$ & $\begin{array}{l}\text { the number of } \\
\text { Compensation wire }\end{array}$ & $\mathrm{K}$ type \\
\hline $\begin{array}{l}\text { Thermocouple } \\
\text { connection form }\end{array}$ & $\begin{array}{l}\text { With M8 thread } \\
\text { connection }\end{array}$ & $\begin{array}{l}\text { external diameter } \\
\text { of wire tube }\end{array}$ & $\leq 4.0 \mathrm{~mm}$ \\
\hline $\begin{array}{l}\text { Thermocouple } \\
\text { connection material }\end{array}$ & $\begin{array}{l}\text { Engineering plastics } \\
\text { tpure copper }\end{array}$ & $\begin{array}{l}\text { Wire connection } \\
\text { form }\end{array}$ & $\begin{array}{l}\text { With M8 thread } \\
\text { connection }\end{array}$ \\
\hline $\begin{array}{l}\text { Thermocouple } \\
\text { connection cores }\end{array}$ & 3 cores & $\begin{array}{l}\text { Wire connection } \\
\text { material }\end{array}$ & $\begin{array}{l}\text { Engineering plastics } \\
+ \text { pure copper }\end{array}$ \\
\hline & & $\begin{array}{l}\text { Wire connection } \\
\text { cores }\end{array}$ & 3 cores \\
\hline
\end{tabular}

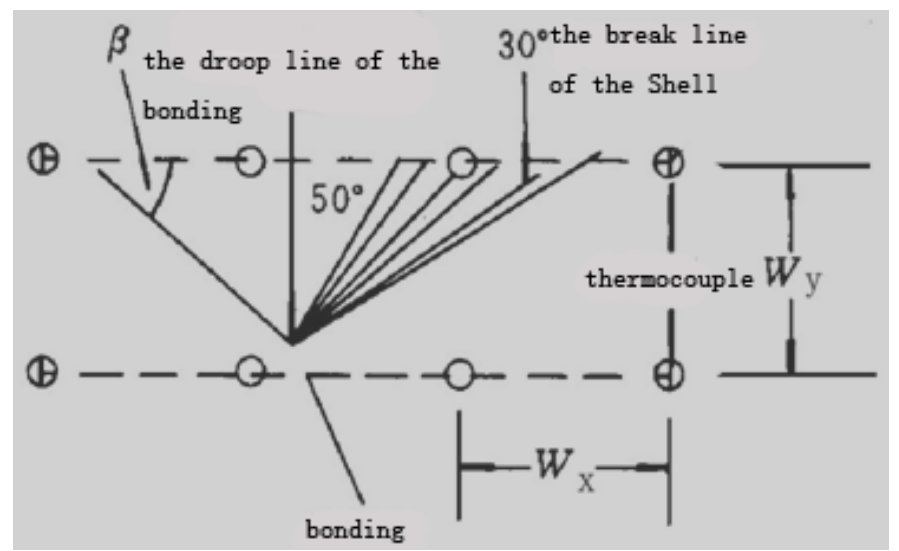

Figure 1. Schematic diagram of fracture line extension bond



Figure 2. Chart of special thermocouple 


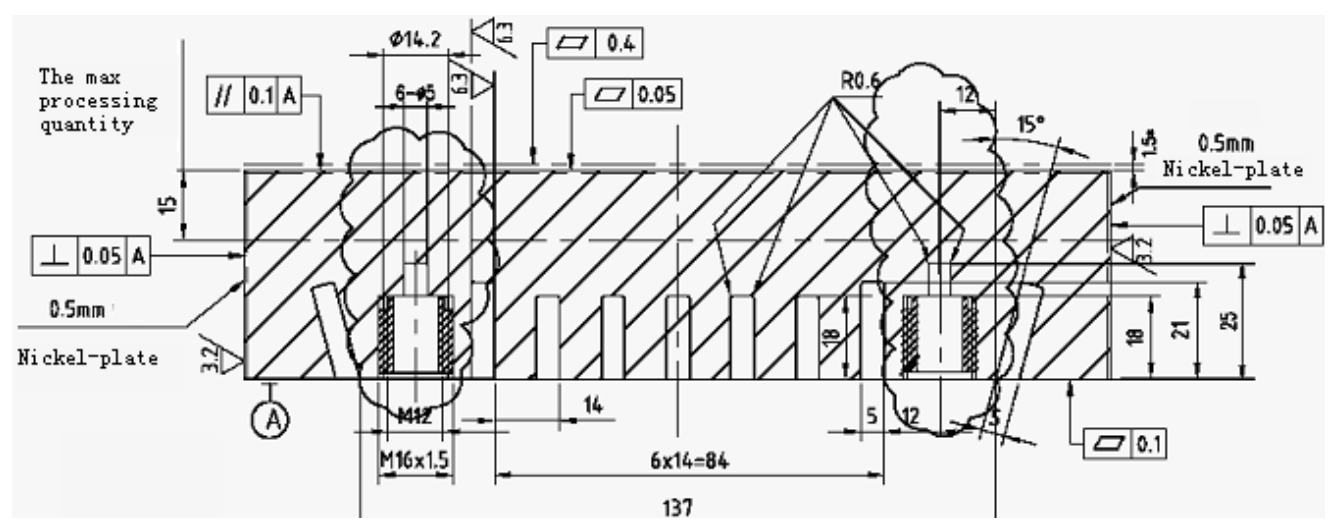

Figure 3. Processing graph of Crystallization copper machine 